\title{
DIREITO E FILOSOFIA: REFLEXÕES SOBRE A JUSTIÇA EM ARISTÓTELES ${ }^{1}$
}

LAW AND PHILOSOPHY: REFLECTIONS ON JUSTICE IN ARISTOTLE

Eduardo Vieira de CARVALHO ${ }^{2}$

Marcos Silvestre GERA ${ }^{3}$

ISSUE DOI: $10.21207 / 2675-0104.2018 .747$

\begin{abstract}
RESUMO
O presente artigo tem como desígnio fornecer uma visão sintética e panorâmica a respeito da virtude da justiça no pensamento aristotélico. Nessa perspectiva, o artigo objetiva compreender a visão que o maior filósofo de toda a Grécia Antiga tinha sobre a virtude ora em tela. Dessa feita, o presente trabalho realiza uma triagem dentro do pensamento sobre o justo em Aristóteles no sentido de selecionar os temas mais pertinentes e merecedores de serem trabalhados com mais afinco e prestígio. O método utilizado para a realização do artigo consiste no bibliográfico, uma vez que o trabalho foi todo desenvolvido por meio da consulta a obras teóricas a respeito do tema.
\end{abstract}

Palavras-chave: Virtude; Aristóteles; Justiça.

\footnotetext{
${ }^{1} \mathrm{O}$ presente artigo sintetiza a monografia de conclusão da pesquisa, realizada para o Programa Interno de Bolsas de Iniciação Científica (PIBIC 2017-2018) da Faculdade de Direito de Franca (FDF), Franca/SP.

${ }^{2}$ Discente da Faculdade de Direito de Franca (FDF), Franca/SP. Bolsista do Programa Interno de Bolsas de Iniciação Científica (PIBIC 2017-2018).

${ }^{3}$ Possui graduação em Filosofia pela Pontifícia Universidade Católica de Minas Gerais (1989), graduação em Educação Física pelas Faculdades Claretianas de Batatais (1989), primeiro ano em Teologia pelo Centro de Estudos da Arquidiocese de Ribeirão Preto (1988) e mestrado em Educação na área de História, Filosofia e Educação pela Universidade Estadual de Campinas (2002). Atualmente é docente da Faculdade de Direito de Franca (FDF), do Centro Universitário de Franca (UNIFACEF) e professor titular da Universidade de Franca (UNIFRAN). Tem experiência na área de Filosofia, com ênfase em Introdução à Filosofia, Ética, Filosofia do Direito, Filosofia da Educação e Antropologia Filosófica.
} 


\section{ABSTRACT}

The purpose of this article is to provide a synthetic and panoramic view of the virtue of justice in aristotelian thought. In this perspective, the article aims to understand the vision that the greatest philosopher of all Ancient Greece had about the virtue now on screen. In this way, the present work performs a triage within the thinking about the fair in Aristotle in the sense of selecting the most pertinent and deserving subjects to be worked with more finesse and prestige. The method used for the accomplishment of the article consists of the bibliographical one, since the work was all developed by consulting theoretical works on the subject.

Keywords: Virtue; Aristotle; Justice.

\section{INTRODUÇÃO}

O propósito que concebe a realização do presente artigo constitui-se em proporcionar uma visão mais filosófica ao estudo do Direito. Nesse sentido, optou-se por estudar panorâmica e sinteticamente a concepção de justiça do maior filósofo de toda a Antiguidade, Aristóteles. Com efeito, seu pensamento jusfilosófico foi considerado o maior já realizado até a Idade Moderna.

Dessarte, o artigo que sintetiza a pesquisa possui como fulcro fornecer um prisma distinto para se olhar o Direito de uma maneira igualmente distinta. De fato, o estudo das reflexões aristotélicas a respeito do justo possibilita entender o fenômeno jurídico de maneira muito mais ampla, diversa e crítica. É justamente em busca desse intuito que o artigo estuda as diferentes dimensões nas quais a justiça em Aristóteles se perfaz.

Sob essa perspectiva plurívoca da justiça em Aristóteles, perceber-se-á que o Filósofo de Estagira a concebe, em um primeiro momento, enquanto virtude universal, haja vista que, sob esse prisma, ela se manifesta em todas as demais virtudes éticas quando dirigidas a outrem.

Posteriormente, identificar-se-á uma dimensão tipicamente singular da justiça no pensamento aristotélico, a qual será tratada enquanto justiça em seu âmbito próprio. De fato, é justamente nessa concepção de justiça que residem as mais importantes e impactantes reflexões do filósofo a respeito da virtude objeto de análise do artigo.

A justiça em sua dimensão própria, portanto, possui sua própria tipificação, a saber: promover a igualdade. A promoção da igualdade entre os sujeitos no tocante a bens externos, portanto, constitui o verbo típico da virtude ora em exame em sua dimensão própria. Ocorre, todavia, que o promover da igualdade entre sujeitos e coisas pode se perfazer de distintas maneiras. 
Caso se busque a promoção da igualdade por meio da distribuição (des)igual de bens, a justiça a ser praticada será a distributiva, a qual, conforme mais a frente se verá, engendra uma desigual partilha de bens conforme a desigualdade existente entre os sujeitos, de modo a manter a proporcionalidade entre bens e pessoas. Nota-se, dessarte, que a igualdade aqui se perfaz por meio de uma proporção geométrica, vez que não toma os sujeitos enquanto iguais ao promover a justiça.

Em outro sentido, caso se objetive promover a igualdade por meio da reparação de um dano ocorrido em uma relação voluntária ou involuntária, a justiça a ser aplicada será a corretiva, a qual opera aritmeticamente, não levando em consideração a desigualdade fática dos indivíduos envolvidos na situação.

Por fim, o artigo se propõe a analisar a razão de ser e o âmbito de incidência da equidade no pensamento aristotélico. De fato, o filósofo de Estagira confere à equidade um dos pontos mais altos de seu pensamento sobre o justo, de modo a conceder ao equo um locus nevrálgico e fundamental dentro de suas reflexões a respeito da justiça.

A compreensão das diferentes manifestações da justiça no pensamento aristotélico oportunizará ao leitor assimilar que, para o autor, essa não se perfaz de maneira rígida, fria e imutável, mas sim se engendra profundamente atrelada à realidade e aos objetivos da pólis, como também aos limites da lei e à contingencialidade da práxis.

\section{CONSIDERAÇÕES INICIAIS A RESPEITO DA VIRTUDE DA JUSTIÇA}

Conforme preleciona Mascaro, não só a filosofia aristotélica representa o píncaro de todo o pensamento grego antigo, mas também a filosofia a respeito do justo em Aristóteles alcança o zênite das questões a respeito da justiça em seu tempo. Com efeito, o pensamento jusfilosófico desenvolvido pelo filósofo de Estagira a respeito da virtude ora em tela foi tão sublime que será considerado, até o início da Idade Moderna, o mais elevado nível de reflexão sobre a justiça já realizado. ${ }^{4}$

Aristóteles, ao refletir sobre a virtude da justiça, confere-a um locus privilegiado em seu pensamento prático. Isso porque, em um

\footnotetext{
${ }^{4}$ MASCARO, Alysson Leandro. Filosofia do Direito. 5. ed. rev., atual. e ampl. São Paulo: Atlas, 2016. p.64.
} 
primeiro momento, diferentemente do estudo das outras virtudes, o filósofo de Estagira concedeu a ela todo um livro de sua mais importante obra a respeito da ética, denominada Ética a Nicômaco. Em um segundo momento, porque a virtude da justiça ganha verdadeiros contornos políticos, haja vista que, segundo Marilena Chauí, seu exercício origina implicações sociais. ${ }^{5}$

Nesse sentido, levando-se em consideração os ensinamentos de Eduardo Bittar e Guilherme de Almeida no tocante à pluralidade de concepções sob as quais a Justiça se concebe, isto é, considerando-se que a Justiça em Aristóteles é de natureza plurívoca e que se perfaz em diferentes dimensões, passa-se ao estudo das mais importantes delas nas linhas que se seguem. ${ }^{6}$

\title{
3 DA JUSTIÇA EM SUA DIMENSÃO UNIVERSAL
}

Aristóteles entende ser a justiça virtude universal haja vista que, sempre que o agente moral agir em relação a outrem de maneira ética, ele terá agido com justiça. Nessa perspectiva, todo exercício ético virtuoso, quando dirigido ao outro, manifesta a justeza do agente. Sob esse viés, preleciona Zingano:

\begin{abstract}
No sentido amplo, é justo quem age segundo as prescrições morais: é justo quem é temperante, generoso, tolerante e assim por diante. Para ser mais preciso, neste sentido amplo, ser justo é equivalente a ser um agente moral na relação com outrem: Como Aristóteles expressamente assinala, a justiça em seu sentido geral é a virtude em geral na medida em que é dirigida aos outros. ${ }^{7}$
\end{abstract}

Já aqui a justiça denota sua natureza eminentemente social, uma vez que ela se perfaz precipuamente em face do outro. Desse modo, diz-se que o agir ético na relação com outrem traduz manifestamente a justeza do agente. Portanto, considera-se sob essa perspectiva que o atuar virtuoso do indivíduo em meio à comunidade segundo as prescrições morais é representação da Justiça em sua acepção universal.

\footnotetext{
${ }^{5}$ CHAUÍ, Marilena. Introdução à história da filosofia: dos pré-socráticos a Aristóteles, volume 1. 2. ed. rev. e ampl. São Paulo: Companhia das Letras, 2002. p. 470-471.

${ }^{6}$ BITTAR, Eduardo Carlos Bianca; ALMEIDA, Guilherme Assis de. Curso de Filosofia do Direito. 5. ed. São Paulo: Atlas, 2007. p.113.

${ }^{7}$ ZINGANO, Marco. Aristóteles: Ethica Nicomachea v1-15: tratado da justiça. tradução e comentário de Marco Zingano; texto grego de Susemihl e Apelt (Leipzig, 1912). São Paulo: Odysseus, 2017. p.34.
} 
Nesse sentido são os ensinamentos de Guilherme de Almeida e Eduardo Bittar, os quais prelecionam que toda virtude, quando diz respeito ao outro, pode ser compreendida enquanto manifestação da justiça. É justamente sob esse prisma que se diz ser a justiça virtude universal e perfeita no tocante ao semelhante, pois todo agir conforme as prescrições morais denotará a virtuosidade e justeza do agente. ${ }^{8}$

Sob essa ótica, Aristóteles considera a justiça em sua acepção universal uma virtude sublime, podendo ser sua perfeição

explicada pelo fato de seu possuidor poder praticá-la dirigindo-se aos outros e não apenas praticá-la isoladamente; com efeito, há muitos que são capazes de praticar a virtude nos seus próprios assuntos privados, mas são incapazes de fazê-lo em suas relações com outrem ${ }^{9}$

É exatamente em razão dessa onipresença do justo no tocante ao exercício virtuoso dirigido a outrem que Aristóteles entende sê-lo a soma de todas as virtudes, de modo a entender que "nem a estrela vespertina nem a matutina tão admiráveis" são quanto a justiça. ${ }^{10}$

Porém, conquanto todo o brilhantismo de Aristóteles em identificar essa dimensão universal do justo no ato ético quando praticado em face ao outro, é em sua esfera particular que residem as mais extraordinárias reflexões sobre a justiça feitas pelo estagirita. Nesse sentido, as linhas seguintes buscarão elucidar as reflexões aristotélicas a respeito da virtude da justiça não em contato com as demais, mas sim dentro de seu próprio campo.

\section{DA JUSTIÇA EM SUA DIMENSÃO PARTICULAR}

Ao passo em que o capítulo anterior tratou da manifestação da justiça em sentido amplo, na qual ela se mostra presente em todas as condutas éticas dirigidas a outrem, o presente capítulo terá como intuito estudá-la em sua esfera própria, ou seja, enquanto justo particular.

\footnotetext{
${ }^{8}$ BITTAR, Eduardo Carlos Bianca; ALMEIDA, Guilherme Assis de. Curso de Filosofia do Direito. 5. ed. São Paulo: Atlas, 2007. p.114-115.

9 ARISTÓTELES. Ética a Nicômaco. Tradução, textos adicionais e notas Edson Bini. São Paulo: EDIPRO, 2014. V, 1, 1129 b 31-35.

${ }^{10}$ Ibidem, 1, 1129 b 28.
} 
Com efeito, é manifesta a cisão estabelecida por Aristóteles entre a dimensão total e a dimensão particular da justiça. Nas próprias palavras do Estagirita: "Assim, a existência de mais de um tipo de justiça é patente, existindo um que difere daquele da virtude como um todo." 11

Essa dimensão particular do justo a que se refere o autor enquanto distinto da "virtude como um todo" consiste exatamente no domínio próprio da justiça. Em outras palavras, já não mais se estudará o justo enquanto agir ético conforme prescrições morais, ou seja, enquanto ato ético no geral dirigido a outrem, mas sim a justiça em sua própria tipificação, singularizada em sua própria existência.

Conforme preleciona Alisson Mascaro, a virtude da justiça também tem sua própria dimensão, não exigindo para sua configuração o acréscimo de nenhuma outra virtude. De acordo com o autor, Aristóteles enxerga enquanto verbo típico da virtude ora em análise a "ação de dar a cada um o que é seu", de modo que essa é exatamente o "regra de ouro sobre justo." 12

Marco Zingano, ao lecionar sobre a dimensão da justiça em questão, ensina que ela se exerce mediante a promoção da igualdade entre ao menos dois sujeitos em relação à coisas exteriores. Tipifica-se a justiça particular, portanto, no ato de promover igualdade entre bens e pessoas. É exatamente essa esfera do justo que, dizendo respeito à igualdade, correlaciona-se com perdas e ganhos, sobressaindo aqui seu caráter notavelmente matemático. ${ }^{13}$

Todavia, o fato é que a dimensão própria do justo admite, conforme o tipo de igualdade presente e a finalidade do ato justo, divisões internas. Nas palavras do Estagirita:

Quanto à justiça particular (parcial) e o justo no sentido que lhe é correspondente, um dos seus tipos é exercido na distribuição de honra, riqueza e demais bens compartilháveis na comunidade política (com efeito, o que é possível aquinhoar aos seus membros em porções desiguais ou iguais). O outro tipo é aquele dotado de um elemento corretivo nos contratos entre particulares. Esse tipo, por sua vez, divide-se em dois subtipos, que dizem respeito às duas

\footnotetext{
${ }^{11}$ ARISTÓTELES. Ética a Nicômaco. Tradução, textos adicionais e notas Edson Bini. São Paulo: EDIPRO, 2014. V, 2, 1130 b 6-7.

${ }^{12}$ MASCARO, Alysson Leandro. Filosofia do Direito. 5. ed. rev., atual. e ampl. São Paulo: Atlas, 2016. p.67.

${ }^{13}$ ZINGANO, Marco. Aristóteles: Ethica Nicomachea v1-15: tratado da justiça. tradução e comentário de Marco Zingano; texto grego de Susemihl e Apelt (Leipzig, 1912). São Paulo: Odysseus, 2017. p.34.
} 
classes de contratos entre particulares, as voluntárias e as involuntárias. $^{14}$

As palavras acima descritas delineiam as duas grandes manifestações da justiça em sentido próprio para Aristóteles: justiça distributiva e justiça corretiva. Seus estudos ocuparão as linhas que se seguem.

\subsection{DA JUSTIÇA DISTRIBUTIVA}

Aristóteles realiza as observações e reflexões a respeito da justiça distributiva no capítulo 3 do Livro V de Ética a Nicômaco. Com efeito, todo o pensamento do estagirita sobre essa justiça se principia com fulcro na premissa de que há "dois indivíduos para os quais existe justiça e duas coisas que são justas." 15

Sob essa perspectiva, o filósofo de Estagira preceitua que o justo, sob o prisma distributivo, resulta necessariamente de ao menos duas porções distintas de justiça, as quais estarão relacionados com dois sujeitos, de modo que essa esfera do justo seja caracterizada como minimamente quádrupla, haja vista que alcança uma associação entre dois sujeitos, entre os quais haverá manifestação do justo, e também duas coisas por eles partilháveis conforme a justeza entre eles existente. ${ }^{16}$

Desse modo, Aristóteles ensina que essa dimensão da justiça engendrará a mesma proporção entre sujeitos e bens exteriores, haja vista que

a proporção entre as coisas será igual à proporção entre os indivíduos, pois não sendo as pessoas iguais, não terão coisas em porções iguais, entendendo-se que na medida em que não são iguais, não receberão em pé de igualdade. ${ }^{17}$

No tocante ao justo distributivo, Mascaro dispõe que se trata da mais sensível e importante manifestação da justiça em Aristóteles. Essa partilha, a qual compreende mínima e necessariamente dois sujeitos e dois bens exteriores, promove a distribuição destes conforme a desigualdade

\footnotetext{
${ }^{14}$ ARISTÓTELES. Ética a Nicômaco. Tradução, textos adicionais e notas Edson Bini. São Paulo: EDIPRO, 2014. V, 2, 1130 b 30 - 1131 a 3.

${ }^{15}$ Ibidem, 3, 1131 a 20-21.

${ }^{16}$ Ibidem, 3, 1131 a 15-25.

${ }^{17}$ Ibidem, 3, 1131 a 22-23.
} 
que há entre os sujeitos. A justa distribuição dos bens, portanto, deve levar em conta necessariamente a (des)igualdade que se perfaz entre os sujeitos. ${ }^{18}$

Sob esse prisma, Eduardo Bittar e Guilherme Almeida ensinam que essa justiça se perfaz no ato de dar a cada um o que é seu, de modo que a justa distribuição consiste em uma mediania a ser determinada "entre os quatro termos de uma relação, sendo dois destes sujeitos que se comparam, e os outros dois, objetos". Nesse sentido, os autores lecionam que a partilha possui como desígnio conferir o que é de cada qual conforme o mérito estabelecido na situação, de modo a evitar a presença dos extremos viciosos, tanto pelo excesso quanto pela falta. ${ }^{19}$

Nota-se, portanto, que a igualdade que se perfaz na partilha e que engendrará a justa distribuição é geométrica, haja vista que, não sendo puramente formal, ela toma os indivíduos enquanto desiguais e realiza a distribuição conforme a sua desigualdade. Ora, nessa senda, a justa distribuição será aquela que partilhar os bens desigualmente conforme a desigualdade dos sujeitos.

Destarte, conforme prelecionam Bittar e Almeida, haverá injustiça sempre que os iguais receberem bens de maneira desigual, assim como haverá injustiça sempre que os desiguais receberem bens exteriores de forma igual. Deste modo, esses dois casos exemplares são representativos da injustiça distributiva, posto que nelas não se observou a desigualdade fática prévia quando da partilha. ${ }^{20}$

Os autores ressaltam ainda a importância de se observar que é justamente a proporcionalidade presente na partilha que determina o caráter geométrico da justa distributividade. Com efeito, a não observação das desigualdades entre os sujeitos leva à inexorável injustiça na distribuição. $^{21}$

Há que se atentar, todavia, que deve existir um critério que paute qual a desigualdade entre os sujeitos que será adotada como parâmetro de proporcionalidade para que se estabeleça a partilha entre eles. Aristóteles, a fim de responder a questão, não tem dúvidas ao indicar ser o mérito o princípio funcional da justa distribuição. É a repartição dos bens conforme

\footnotetext{
${ }^{18}$ MASCARO, Alysson Leandro. Filosofia do Direito. 5. ed. rev., atual. e ampl. São Paulo: Atlas, 2016. p.68.

${ }^{19}$ BITTAR, Eduardo Carlos Bianca; ALMEIDA, Guilherme Assis de. Curso de Filosofia do Direito. 5. ed. São Paulo: Atlas, 2007. p. 117.

${ }^{20}$ Ibidem, p. 118.

${ }^{21}$ Ibidem, p.118.
} 
o mérito dos indivíduos que conceberá, segundo o estagirita, a justa distribuição. $^{22}$

Ressalva-se, todavia, que não se pode ler o termo "mérito" pelos olhares contemporâneos. De fato, o próprio filósofo chama a atenção para a subjetividade desse, uma vez que "para os adeptos da democracia tratase da liberdade, para os adeptos da oligarquia trata-se da riqueza ou bom nascimento, enquanto para aqueles da aristocracia trata-se da virtude. $\mathrm{O}$ justo é, portanto, certo tipo de proporcional". ${ }^{23}$

Marilena Chauí, dissertando sobre essa modalidade da justiça em Aristóteles, ensina sê-la de natureza eminentemente política, haja vista que, partindo da própria realidade concreta da pólis, objetiva dar a cada um o que é seu conforme as suas desigualdades, de modo a, pelo tratamento desigual dos desiguais, estabelecer a igualdade ao final. ${ }^{24}$

A desigualdade fática entre os sujeitos e a consequente diferença de mérito entre eles deve ser levada em consideração quando da partilha a fim de que essa seja justa. Com efeito, nota-se que a igualdade não é premissa da justiça ora em tela, mas sim propósito final.

Concluindo-se as reflexões sobre a justiça distributiva, ressaltase que essa é por Chauí denominada de fundante, dado que seu funcionamento transcende a dimensão jurídica e alcança a própria dimensão social e política da vida. A autora, portanto, conclui seu raciocínio chamando a atenção para a importância dessa dimensão da justiça em Aristóteles na medida em que ela possui como objetivo inibir rebeliões e motins, os quais são tidos por Aristóteles como os maiores motivos de corrompimento da pólis. Evidencia-se assim toda a crucial dimensão política assumida pela justiça distributiva, considerada pelo filósofo de Estagira como responsável por preservar a paz social por meio da coesão da pólis e o equilíbrio entre os indivíduos. ${ }^{25}$

\subsection{DA JUSTIÇA CORRETIVA}

\footnotetext{
${ }^{22}$ ARISTÓTELES. Ética a Nicômaco. Tradução, textos adicionais e notas Edson Bini. São Paulo: EDIPRO, 2014. V, 3, 1131 a 25-26.

${ }^{23}$ ARISTÓTELES. Ética a Nicômaco. Tradução, textos adicionais e notas Edson Bini. São Paulo: EDIPRO, 2014. V, 3, 1131 a 26 - 29.

${ }^{24}$ CHAUÍ, Marilena. Introdução à história da filosofia: dos pré-socráticos a Aristóteles, volume 1. 2. ed. rev. e ampl. São Paulo: Companhia das Letras, 2002. p. 470.

${ }^{25}$ Ibidem, p.470.
} 
Uma vez que foi vista no capítulo anterior a dimensão da justiça que se faz no distribuir e no partilhar, passa-se agora ao estudo da justiça denominada por Aristóteles como corretiva. As reflexões sobre ela encontram-se no capítulo quatro do Livro V de Ética a Nicômaco.

De acordo com o estagirita, sua função, como o próprio nome já indica, é de reparar um prejuízo provocado tanto nas relações voluntárias quanto nas involuntárias. O justo, o qual sob essa perspectiva já não se tipifica por meio de uma distribuição, mas sim de uma correção, perfaz-se com fulcro em uma proporção aritmética, não levando em consideração a desigualdade entre os indivíduos ${ }^{26}$, pois

não faz qualquer diferença se alguém bom trapaceou alguém mau ou se este trapaceou aquele, nem se foi um homem bom ou mau que cometeu adultério; a lei apenas contempla a natureza característica do dano, tratando as partes como iguais, apurando simplesmente se alguém praticou injustiça enquanto o outro indivíduo a sofreu, e se alguém produziu o dano enquanto alguém foi por ele atingido ${ }^{27}$

Nota-se, destarte, que a justiça corretiva não leva em consideração a desigualdade fática dos sujeitos. Dessa forma, conforme preleciona o estagirita, não importa se alguém mau lesa alguém bom. $\mathrm{O}$ que realmente interessa sob esse prisma é o dano ocasionado, o que leva Zingano a dispor que, em relação a essa modalidade de justiça, a reparação deve ser equivalente ao dano causado, sem que se leve em consideração a condição social das pessoas envolvidas. ${ }^{28}$

Ressalta-se, deste modo, toda a imparcialidade do julgador, o qual, objetivando medir o dano e lhe estabelecer uma correção equivalente, não deve colocar em julgamento as pessoas envolvidas, mas tão somente o prejuízo provocado.

Faz-se a ressalva, porém, que essa dimensão da justiça admite dois campos distintos, pois ela pode se perfazer tanto na correção de um prejuízo ocasionado em uma relação voluntária (como o caso de compra e

\footnotetext{
${ }^{26}$ ARISTÓTELES. Ética a Nicômaco. Tradução, textos adicionais e notas Edson Bini. São Paulo: EDIPRO, 2014. V, 4, 1131 b $25-1132$ a 2.

${ }^{27}$ Ibidem, 4, 1132 a 2-8.

${ }^{28}$ ZINGANO, Marco. Aristóteles: Ethica Nicomachea v1-15: tratado da justiça. tradução e comentário de Marco Zingano; texto grego de Susemihl e Apelt (Leipzig, 1912). São Paulo: Odysseus, 2017. p. 45-47.
} 
venda, por exemplo), tanto quanto pode se perfazer na correção de um dano provocado em uma relação involuntária (como é o caso do furto).

Eduardo Bittar e Guilherme Almeida, no tocante a essa divisão da justiça corretiva em duas vertentes conforme a natureza do liame estabelecido entre os sujeitos, ensinam que se a relação for de origem voluntária, a justiça corretiva pode ser denominada de comutativa, sendo destinada às relações nas quais prevaleçam a liberdade das partes e a vontade de estabelecer o vínculo. Caso haja algum prejuízo na relação, recorre-se, por meio da justiça comutativa, a uma medida corretiva para que se reestabeleça a igualdade entre as partes. ${ }^{29}$

De outro modo, no tocante às relações involuntárias, os autores precisam que a correção toma a natureza de reparação, de modo que o causador do dano deve receber uma devida sanção por ter causado uma lesão indevida ao outro, da mesma maneira que a vítima que sofreu a lesão deve ser reparada ou recompensada posteriormente relativamente à perda que suportou. ${ }^{30}$

Com fulcro no raciocínio acima desenvolvido e nesse mesmo sentido, Mascaro preleciona que essa dimensão da justiça entendida enquanto corretiva e que opera aritmeticamente - sem levar em consideração a posição social e a desigualdade presente entre os sujeitos será aquela engendrará a lógica da responsabilidade civil. ${ }^{31}$

\section{$5 \quad$ DA EQUIDADE}

Muito embora a dimensão da justiça distributiva seja considerada por Mascaro como o âmbito mais sensível e mais alto a respeito do justo em Aristóteles, o próprio autor assevera que o pensamento aristotélico no tocante à justiça alcança seu pináculo na apologia da equidade. ${ }^{32}$

Nesse sentido, a presente reflexão tem por intuito não só analisar, mas compreender a equidade dentro do pensamento jusfilosófico do estagirita, correlacionando-a com a justiça como um todo e com a própria

\footnotetext{
${ }^{29}$ BITTAR, Eduardo Carlos Bianca; ALMEIDA, Guilherme Assis de. Curso de Filosofia do Direito. 5. ed. São Paulo: Atlas, 2007. p. 121.

${ }^{30}$ BITTAR, Eduardo Carlos Bianca; ALMEIDA, Guilherme Assis de. Curso de Filosofia do Direito. 5. ed. São Paulo: Atlas, 2007. p. 123.

${ }^{31}$ MASCARO, Alysson Leandro. Filosofia do Direito. 5. ed. rev., atual. e ampl. São Paulo: Atlas, 2016. p. 69.

${ }^{32}$ Ibidem, 78.
} 
lei, de modo a identificar seu âmbito de aplicabilidade e sua razão de ser no pensamento de Aristóteles.

Com efeito, o filósofo, ao longo do capítulo 10 do Livro $\mathrm{V}$ de Ética a Nicômaco, versa sobre a correlação do justo com o equitativo e da justiça com a equidade. De fato, preleciona o autor ser o equitativo uma dimensão mais alta de justiça, a qual possui sua natureza no aperfeiçoamento da justiça legal. ${ }^{33}$

Conforme preceitua o estagirita, a existência da dimensão do equitativo surge e se consolida na medida em que, dada a inexorável generalidade da lei advinda de seu caráter abstrato, sempre haverá casos nos quais, em razão de suas especificidades, seja impossível aplicar a legislação de modo a preservar o justo. Isso se dá em razão de que enquanto as normas legislativas são estanques e cristalizadas, a práxis é contingencial e variável. ${ }^{34}$

Acerca do assunto, Eduardo Bittar e Guilherme de Almeida consideram ser a equidade de fulcral importância para a realização da justiça, pois dada a "impossibilidade de haver uma legislação minimamente detalhista e futurista", faz-se necessário lançar mão do equo, o qual converge seu âmbito de atuação exatamente para os casos nos quais, em virtude de suas especificidades e singularidades, sejam impossíveis de serem deslindados da maneira justa pela legislação existente. ${ }^{35}$

Os autores, nesse sentido, preconizam que a equidade se perfaz de modo que o juiz, ao se deparar com um caso não previsto ou que seja impossível de ser regulado por lei, decide como se o próprio legislador, ao se deparar com aquela situação fática, prescrevesse ao caso uma lei específica, ou seja, uma lei que só tivesse validade para ele. Desta feita, concluem Bittar e Almeida que "é na ausência da lei que a equidade guarda sua utilidade maior, sobretudo complementando, particularizando e respondendo pelo que quedou imprevisto." 36

No que concerne à equidade em Aristóteles, Zingano sustenta a tese de que ela se manifesta na qualidade de reparação do justo legal. Segundo o autor, sua justificativa se inicia pela própria análise da lei: uma vez que essa é imperiosamente universal e consolidada, e o domínio sobre o qual ela é destinada (a práxis) é notadamente marcado pela

\footnotetext{
${ }^{33}$ ARISTÓTELES. Ética a Nicômaco. Tradução, textos adicionais e notas Edson Bini. São Paulo: EDIPRO, 2014. V, 10, 1137 b 1-10.

${ }^{34}$ Ibidem, 10, 1137 b 11-25.

${ }^{35}$ BITTAR, Eduardo Carlos Bianca; ALMEIDA, Guilherme Assis de. Curso de Filosofia do Direito. 5. ed. São Paulo: Atlas, 2007. p. 134.

${ }^{36}$ Ibidem, p. 135 .
} 
contingencialidade e pela variabilidade, é possível que haja um vazio marcado pela desarmonia entre o que a lei objetiva e o que realmente se atingiria caso o juiz aplicasse a letra da lei. Nesse sentido, a equidade expressa-se mediante uma reposição aperfeiçoada da justiça objetivada pela lei consoante as singularidades do caso concreto. ${ }^{37}$

Mascaro, nessa mesma lógica, coloca em evidência a equidade enquanto um instrumento importantíssimo responsável pela correção legal, uma vez que atua dentro das lacunas da lei, no interior da legislação, estendendo o tratamento justo até os casos mais singulares da práxis, os quais a princípio não poderiam ser solucionados pelas leis. ${ }^{38}$

Encerra o professor seu raciocínio destacando que reside na equidade o aspecto circunstancial da justiça, pois sua prática se demonstra enquanto um casuístico artesanato atento às especificidades do mundo da vida. A coroação da justiça no pensamento aristotélico ocorre, portanto, com a aceitação dos limites da lei e a consequente utilização do equo, ou seja, do exercício atento, humilde e compreensível de uma realidade variável, mutante, contingente, viva enfim. ${ }^{39}$

\section{CONSIDERAÇÕES FINAIS}

Conforme se pôde depreender da leitura do artigo, a virtude da justiça ocupa uma posição de vital importância no pensamento aristotélico. De acordo com o que se conferiu, isso se dá em razão de que ela estabelece uma transição entre a ética e a política, uma vez que seu exercício enquanto virtude ética acarreta consequências políticas.

Com efeito, a natureza eminentemente social da justiça se destaca na medida em que sua ação se tipifica na promoção da igualdade entre sujeitos e coisas, de sorte que sua prática constitui um contínuo exercício de promover a igualdade entre pessoas em relação a bens conforme a proporcionalidade considerada e o objetivo preconizado pelo agir justo.

Dessa forma, como acima lido, a ação justa é a que promove a igualdade. Aristóteles, todavia, conhecedor e atento à realidade que o cercava, identificou dois tipos de justiça. Àquela que se tipifica

\footnotetext{
${ }^{37}$ ZINGANO, Marco. Aristóteles: Ethica Nicomachea v1-15: tratado da justiça. tradução e comentário de Marco Zingano; texto grego de Susemihl e Apelt (Leipzig, 1912). São Paulo: Odysseus, 2017. p.61. ${ }^{38}$ MASCARO, Alysson Leandro. Filosofia do Direito. 5. ed. rev., atual. e ampl. São Paulo: Atlas, 2016. p.79.

${ }^{39}$ Ibidem, p.80.
} 
proporcionando uma desigual distribuição de bens conforme a desigualdade dos sujeitos Aristóteles dá o nome de justiça distributiva. Àquela que, por sua vez, opera aritmeticamente, buscando corrigir um quinhão que foi lesado em uma relação voluntária ou involuntária, o estagirita dá o nome de corretiva.

O presente artigo ainda contemplou a justiça enquanto virtude universal (uma vez que se faz presente em todas as demais virtudes quando praticadas no meio social) e a equidade. De fato, o equo, ou seja, o agir equitativo, constitui a representação mais clara do reconhecimento de Aristóteles dos limites da lei e da contingencialidade da práxis. Com efeito, seu exercício, ao consistir em um atuar compreensivo e atento ao mundo, denota e simboliza a teoria da justiça em Aristóteles: humilde, cuidadosa e vigilante em combater as desigualdades nas pólis. Por isso e por tudo que se buscou demonstrar, resta claro o porquê da justiça ocupar um locus tão excelso no pensamento prático aristotélico.

\section{REFERÊNCIAS BIBLIOGRÁFICAS}

ARISTÓTELES. Ética a Nicômaco. Tradução, textos adicionais e notas Edson Bini. São Paulo: EDIPRO, 2014.

BITTAR, Eduardo Carlos Bianca; ALMEIDA, Guilherme Assis de. Curso de Filosofia do Direito. 5.ed. São Paulo: Atlas, 2007.

CHAUÍ, Marilena. Introdução à história da filosofia: dos pré-socráticos a Aristóteles, volume 1. 2.ed., rev. e ampl. São Paulo: Companhia das Letras, 2002

MASCARO, Alysson Leandro. Filosofia do Direito. 5. ed. rev., atual. e ampl. São Paulo: Atlas, 2016.

ZINGANO, Marco. Aristóteles: Ethica Nicomachea v1-15: tratado da justiça. Tradução e comentário de Marco Zingano; texto grego de Susemihl e Apelt (Leipzgig, 1912). São Paulo: Odysseus, 2017. 